1. MBBS, MCPS,

FCPS (General Surgery)

Assistant Professor Surgery

Hamdard College of Medicine and

Dentistry,

Hamdard University Karachi.

2. MBBS, MS (General Surgery)

Assistant Professor

Department of Surgery

Liaquat University of Medical \&

Health Sciences Jamshoro /

Hyderabad.

3. MBBS, MS (General Surgery)

Assistant Professor

Department of Surgery

Liaquat University of Medical \&

Health Sciences Jamshoro /

Hyderabad.

4. MS (General Surgery)

Assistant Professor

Department of Surgery

People's University of Medical \&

Health Sciences Nawabshah

5. MBBS

Resident Surgery

Liaquat University of Medical \&

Health Sciences Jamshoro /

Hyderabad.

6. BDS, MSc, M.Phil, Ph.D

Research Officer / Associate

Community Dentistry,

Liaquat University of Medical \&

Health Sciences

Jamshoro / Hyderabad Sindh

Pakistan.

Correspondence Address:

Dr. Irfan Haider Mangi

Flate No. 4, Block 13,

Ground Floor VIP Apartment,

Gulistan-e-Sajjad Hyderabad, Sindh

Pakistan.

farooq346@gmail.com

Article received on:

06/02/2019

Accepted for publication:

$25 / 05 / 2019$

\section{CORRELATION OF SURGICAL SITE INFECTION (SSI) AFTER APPENDICECTOMY WITH PER-OPERATIVE MORPHOLOGICAL APPEARANCE OF APPENDIX.}

\begin{abstract}
Rehana Firdos ${ }^{1}$, Irfan Haider Abdi $^{2}$, Qambar Ali Laghari ${ }^{3}$, Mujeeb ur Rahman Sahito ${ }^{4}$, Naimatullah Kalhoro5, Sikandar Munir Memon ${ }^{6}$

ABSTRACT: Acute appendicitis is the most common cause of emergency abdominal surgery worldwide. Postoperatively, surgical site infection (SSI) occurs in $3 \%$ to $60 \%$ of appendicectomized patients, depending on pathological state of appendix. SSI is a devastating complication from biologic and economic point of view and has enormous impact on patient's quality of life. Objectives: To determine the frequency of surgical site infection after appendicectomy in patients presenting as acute appendicitis and correlate it with per-operative morphological appearance of appendix. Study Design: Cross-sectional study. Setting: Department of General Surgery, Liaquat University of Medical and Health Sciences Jamshoro. Period: March 2015 to February 2016. Material \& Methods: This study was carried out on 200 patients. All male and female patients above age of 12 years with clinical diagnosis of acute appendicitis or localized peritonitis due to perforated appendix undergoing appendectomy by grid iron incision and whose skin closed primarily by interrupted silk $2 / 0$ stitches were included in the study. Operative findings were recorded and inflammation of appendix was graded into four categories. Postoperatively patients were followed for period of 30 days to check the development of SSI. Results: Out of 200 patients, 42 suffered from SSI (21\%). On the basis of per-operative morphological appearance of appendix, uncomplicated appendicitis was significantly high 135(67.5\%) than complicated appendicitis 65(32.5\%). SSI developed in 12(28.5\%) cased of uncomplicated and $30(71.5 \%)$ cases of complicated appendicitis. Conclusion: It was not possible to establish a relationship between SSI and per-operative morphological appearance of appendix. Frequency of $\mathrm{SSI}$ reported here $(21 \%)$ is comparable with literature. We recommended that avoiding delay in diagnosis, use of peri-operative antibiotics, sound surgical technique to avoid wound contamination and continuing surveillance is necessary to further reduce SSI rates after open appendicectomy.
\end{abstract}

Key words: Appendix, Acute Appendicitis, Intra-abdominal Abscess, Open Appendicectomy, Surgical Site Infection, Wound Infection.

Article Citation: Firdos R, Abdi IH, Laghari QA, Sahito M, Kalhoro N, Memon SM. Correlation of Surgical Site Infection (SSI) after appendicectomy with per-operative morphological appearance of appendix. Professional Med J 2020; 27(2):251-259. DOI: 10.29309/TPMJ/2020.27.2.3231

\section{INTRODUCTION}

Acute appendicitis is the commonest cause of acute abdomen. ${ }^{1}$ The surgeons have been confronting the acute appendicitis since it was first described in 1886 by $\mathrm{R} \mathrm{H} \mathrm{Fitz} 1^{2}$, its diagnosis still remains a dilemma to almost all of the surgeons, at least some point in their practice. ${ }^{3}$

Acute appendicitis is classified as simple, gangrenous or perforated on basis of operative findings and histologic appearance. ${ }^{4}$ The overall mortality rate for appendicitis is less than $1 \%$. The morbidity depends on whether the appendix is acutely inflamed or perforated. ${ }^{5}$ The rate of perforation varies from $16 \%$ - 40\%. Appendiceal perforation is associated with increased morbidity and mortality, compared to non perforating appendicitis. ${ }^{6}$

Early appendicectomy is traditionally considered the treatment of choice for acute appendicitis. ${ }^{7}$ Risk factors for adverse outcomes after the surgical treatment of appendicitis in adults are poorly defined. ${ }^{8}$ The pathological state of appendix is the most important determinant of postoperative infection. ${ }^{9}$ Intra-operative appendicitis severity 
score (IASS: 0 - 3) can identify patients more likely to suffer morbidity following emergency appendicectomy. Score 0: No inflammation, score 1: engorged appendix / no peritonitis, score 2: peritoneal reaction/exudates, score 3; evidence of gangrene, perforation or abscess formation. ${ }^{10}$

Postoperative complications are typically infectious complications. ${ }^{5}$ Wound infection is the most common postoperative complication occurring in 5 to $10 \%$ of all patients. Wound infection after appendicectomy for perforative or gangrenous appendicitis is four to five times higher than for early disease. Intra-abdominal abscess, most commonly pelvic, occur postoperatively in about $5 \%$ of cases of perforated appendicitis. ${ }^{5}$

Wound infection has probably always been a major complication of surgery and trauma. It has been documented for at least 4000 to 5000 years. In 1600s, wound infection was so common that redness, warmth, and purulence were thought to desirable features o wound healing. The preoperative use of antimicrobial agents has had a greater favorable impact on the prevalence of postoperative infection than any other measures introduced since the original discovery of importance of surgical antisepsis.

Recently, the U.S Centres for Disease Control and Prevention (CDC) reviewed and revised the terminology and definitions of wound infections to be consistent with surgical terminology. All postoperative surgical infections occurring in an operative site are now termed surgical site infections (SSIs). For sub-classification SSIs are defined as superficial incisional (involving only skin and subcutaneous tissue), deep incisional (involving fascial and muscle layers of incision), and organ space (involving any part of anatomy e.g. organs or space, other than the incision, that was opened or manipulated during operative procedure). Organ space SSIs include postoperative intra-abdominal abscesses, empema or mediastinitis.

SSI continues to be a major source of morbidity following operative procedures. Despite many decades of application of refined surgical techniques, environmental changes in operating room and the use of preventive antibiotics, infection at the surgical site remains a too common events.

The purpose of our study was to determine the frequency of SSI after appendicectomy and correlate it with per-operative morphological appearance of the appendix, in Ward-26 (Unit III) of Jinnah Postgraduate Medical Centre, Karachi. After through search, we found a gap in literature on this particular topic and decided to conduct our study and the information gained by this study has helped us in better management and reducing postoperative complications, in patients who suffer from this common but potentially dangerous disease.

\section{MATERIAL AND METHODS}

This cross-sectional study was carried out on 200 patients for the period of one year from March 2015 to February 2016 in the Department of General Surgery, Liaquat University of Medical and Health Sciences Jamshoro. All male and female patients above age of 12 years with clinical diagnosis of acute appendicitis or localized peritonitis due to perforated appendix undergoing appendectomy by grid iron incision and whose skin closed primarily by interrupted silk $2 / 0$ stitches were included in the study. While all male and female patients who were having co-morbid factors like diabetes mellitus, obesity, pregnancy, malnutrition, malignancy, skin infection were excluded from study group.

All patients with clinical diagnosis of acute appendicitis and localized peritonitis secondary to perforated appendix, who fulfilled the inclusion criteria were collected through proforma, from accident and emergency department of Jinnah Postgraduate Medical Centre, Karachi and were evaluated by detailed history, clinical examination and relevant investigations like blood $\mathrm{CP}$, urine $D / R$, ultrasound pelvis in female patients. In all patients pre-operatively 1 gram injection Ampicilline and $500 \mathrm{mg}$ injection Metronidazole were given as prophylactic antibiotics, at the time of induction of anesthesia. All patients were operated by open appendectomy under general 
anesthesia. Mean duration of operation was 45 minutes.

\section{Operative Technique}

Skin pre-operative with $1 \%$ povidine iodine solution. Skin incised by grid iron incision in all cases. Subcutaneous fat and fascia were incised. The aponeurosis of external oblique muscle was incised in the direction of its fibres. The internal oblique and transverses abdominis muscle were split open. Peritoneum was incised, any pus or fluid which came out was immediatelty sucked and mopped. Appendix was identified by following three taemiae coli of caecum. Appendix was delivered into wound and a note was made of degree of inflammation of appendix (whether acutely inflamed, suppurative, gangrenous or perforated). Appendix was held with Babcock forceps. The base of mesoappendix was clamped in a hemostat, divided and ligated with chromic $2 / 0$. The base of appendix was crushed, ligated with chromi $2 / 0$ and cut above the ligature. The mucosa of the appendical stump was fulgurated with the electrocautry. Operative field was checked for hemostatis. If there was considerable purulent fluid in the retro caecal space or in the pelvis, then a soft silastic drain was inserted through a separate stab incision, in cases of perforated appendicitis. Peritoneum closed with continuous $2 / 0$ chromic. Transversus abdomins and internal oblique muscles were closed with interrupted 2/0 chromic catgut. Aponeurosis of external oblique was closed with continuous 2/0 chromic catgut. Scarpa's facia was approximated by interrupted $2 / 0$ chromic. Skin closed primarily in all cases with interrupted silk 2/0 stitches. Dressing done with sterile gauze. All appendices were sent for histopathological examination.

\section{Postoperative Management}

All patients were put on postoperative antibiotics. Only 3 doses of injection Ampicilline 500 mg, Injection Metronidazole 500mg and injection Gentamycin $80 \mathrm{mg}$ intravenously were give in cases of acutely inflamed appendix, while in cases of supportive, gangrenous or perforated appendix 3 doses of injection Ampicilline $500 \mathrm{mg}$, injection Metronidazole 500mg, injection Gentamycin $80 \mathrm{mg}$ were followed by the broad spectrum oral antibiotics for 5 days.

In cases of perforated appendicitis drain was taken out on $3^{\text {rd }}$ or $4^{\text {th }}$ postoperative day. Wound was examined before discharging the patient. Subsequently, the patients were observed on $5^{\text {th }} 7^{\text {th }}, 15^{\text {th }}, 21^{\text {st }}$ and $30^{\text {th }}$ day in surgical outpatient department for occurrence of SSI. Surgical site infections were divided into three categories depending on the severity i.e. superficial incisional depending on the severity i.e. superficial incisional, deep incisional and organ space SSI.

In patients who developed superficial or deep SSI, stitches were removed and wound was opened for drainage of pus, specimen of pus was sent culture and sensitivity. Superficial and deep SSI were managed by daily dressing in outpatient department, while patients with organ. space infection were re-admitted and managed by intravenous antibiotics and ultrasound guided percutaneous drainage of abscesses.

\section{Statistical Analysis}

Data analysis was performed through SPSS version-16. $M: F$ was computed to present sex distribution. Age of the patient was presented by mean \pm standard deviation.

Frequency and percentages were computed to present patients presenting complaints, signs of acute appendicitis, position of appendix, raised total leukocyte counts and neutrophil counts, peroperative morphological appearance of appendix and surgical site infections. Chi square test was applied to determine any relationship between any relationship between surgical site infection and morphological appearances of appendix. Statistical significance was considered if $P<$ 0.05 .

\section{RESULTS}

Out of total 200 patients of acute appendicitis, there were $134(67 \%)$ male and 66 (33\%) female with 1:2 male to female ratio. Mean age of the patients was observed. Mean \pm S.D $=24.04 \pm 9.36$ (ranging from 13 -55 years). Majority of patients presented with duration of symptoms lasting for 48 hours. Abdominal pain was the commonest 
presenting complaint that was present in all 200 $(100 \%)$ followed by nausea $(76 \%)$, fever $(64.5 \%)$, vomiting (58\%) and anorexia (56\%).

Signs of acute appendicitis were evaluated, rebound tenderness in RIF was the commonest signs that was observed in 176 (88\%) patients followed by tenderness in RIF in 166 (83\%), cough sign in 146 (73\%) Rovsign sign 66(33\%) and oburator sign in 24 * $(12 \%)$ patients.

Retrocaecal was the commonest position that was found in $152(76 \%)$ patients followed by pelvic in $24(12 \%)$, pre-ileal in $11(5.5 \%)$, subcaecal in 9 $(4.5 \%)$ and post-ileal in $3(1.5 \%)$ patients.

Elevated total leukocyte count (TLC $>11000 \mathrm{~mm} 3$ ) was found in $150(75 \%)$ patients while elevated neutrophill count $(>70 \%)$ was found in 161 (80.5\%) patients.

Morphological appearances of appendix were observed per-operatively. Uncomplicated or low risk appendicitis included acutely inflame and suppurative appearances while complicated or high risk appendicitis included gangrenous and perforated appearances. Figure-1

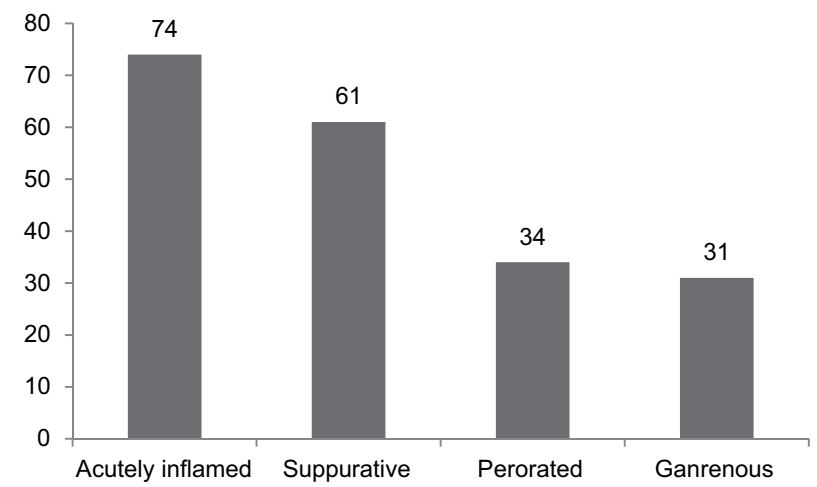

Figure-1. Peroperative morphological appearance of appendix $(n=200)$

\section{Low risk appendicitis = acute inflammation + suppurative}
2. High risk appendicitis = Gangrenous + perforation

Low risk appendicitis were significancy higher than high risk appendicitis $(67.5 \% \mathrm{Vs} 32.5 \%, \mathrm{P}=$ $<0.001)$.
Surgical site infection occurred in total 42 (21\%) patients as superficial incisional infection in 28 (14\%), deep incisional infection in 10 (5\%), while organ / space infection in 28 (14\%), deep incisional infection in 10 (5\%), while organ/space infection occurred in only $4(2 \%)$ patients in our study. Figure-2

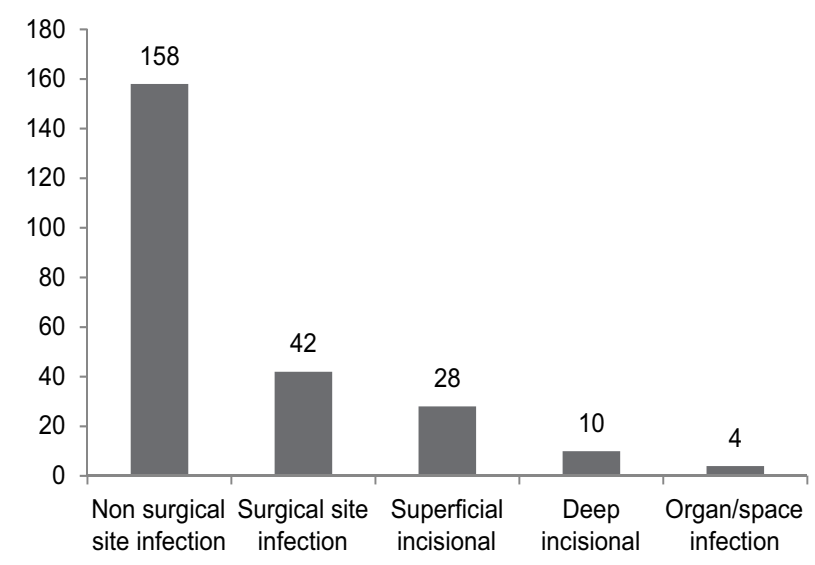

Figure-2. Frequency of surgical site infection $(n=200)$

Out of $74(37 \%)$ acutely inflamed appendicitis, $5(6.7 \%)$ had superficial SSI. While none had organ / space SSI. Out of 61 (30.5\%) suppurative appendicitis, 6 99.8\%) had superficial SSI, 1 $(1.63 \%)$ had deep incisional SSI while non had organ / space SSI. Out of $31(15.5 \%)$ gangrenous appendicitis, 8 (25.8\%) had super ficial SSI, 3(9.7\%) had deep SSI. While none had organ / space SSI. Out of 34 (17\%) perforated appendicitis, 9(26.4\%) had superficial SSI, 6 (17.6\%) had deep SSI, while 4 (11.8\%) had organ / space SSI. Data revealed insignificant relationship between surgical site infection and morphological appearance of appendix $\left(X^{2}=\right.$ 9.173 $\mathrm{P}=0.164)$. Table-I

Culture sensitivity of pus from 42 infected wounds revealed that most common pathogen isolate was E-col (42\%), followed by staph-aureus (11.9\%), psueomonas (9.5\%) and klebsiella (4.7\%). There was no mortality in this study.

Table-Il Provides comparison of SSI rate of present study with other similar studies. 


\begin{tabular}{|c|c|c|c|c|}
\hline $\begin{array}{l}\text { Surgical site infection } \\
\qquad(n=21)\end{array}$ & $\begin{array}{l}\text { Acutely inflamed } \\
(n=74)\end{array}$ & $\begin{array}{l}\text { Suppurative } \\
(\mathrm{n}=61)\end{array}$ & $\begin{array}{l}\text { Gangrenous } \\
(n=31)\end{array}$ & $\begin{array}{l}\text { Perforated } \\
(\mathrm{n}=34)\end{array}$ \\
\hline $\begin{array}{l}\text { Superficial incisional } \\
(\mathrm{n}=28)\end{array}$ & $5(6.7 \%)$ & $6(9.8 \%)$ & $8(25.8 \%)$ & $9(26.4 \%)$ \\
\hline $\begin{array}{l}\text { Deep incisional } \\
(\mathrm{n}=10)\end{array}$ & 0 & $1(1.6 \%)$ & $3(9.6 \%)$ & $6(17.6 \%)$ \\
\hline $\begin{array}{l}\text { Organ / space infection } \\
(n=04)\end{array}$ & 0 & 0 & 0 & $4(11.7 \%)$ \\
\hline
\end{tabular}

\begin{tabular}{|l|c|c|c|}
\hline Study Conducted by & Total No. of Patients & $\begin{array}{c}\text { SSI rate in Uncomplicated } \\
\text { Appendicitis }\end{array}$ & $\begin{array}{c}\text { SSI Rate in Complicated } \\
\text { Appendicitis }\end{array}$ \\
\hline Edino ST ${ }^{(70)}$ & 142 & $28.9 \%$ & $47.4 \%$ \\
\hline Harahshe M ${ }^{(108)}$ & 72 & $20.0 \%$ & $51.5 \%$ \\
\hline Alkanderi M ${ }^{(124)}$ & 160 & $7.8 \%$ & $38.0 \%$ \\
\hline Gulzar S $^{(43)}$ & 180 & $7.4 \%$ & $30.0 \%$ \\
\hline Present study & 200 & $28.5 \%$ & $71.5 \%$ \\
\hline & \multicolumn{2}{|r|}{ Table-II. Comparison of SSI rate uncomplicated and complicated with different studies. } \\
\hline
\end{tabular}

\section{DISCUSSION}

Appendicectomy is the most common emergency surgical procedure worldwide. ${ }^{11}$ Appendectomy is regarded as a simple operation in most cases, after which major complications are uncommon. ${ }^{12}$ The most frequent adverse outcomes are surgical would infection and intraabdominal complications. ${ }^{13}$ The reported rates of wound infection vary from $3 \%$ to as high as $60 \%$ depending on the pathological state of appendix ${ }^{14}$, whether the appendix is acutely inflamed or perforated. When appendix is gangrenous or perforated with per-appendicitis the incidence of septic complications reaches as much as $30 \%$, these include surgical would infection and intra abdominal abscess formation. ${ }^{15}$ Post operative would infections have an enormous impact on patients quality of life and potential consequences for the patient range from increased pain and care of an open would to sepsis and even death. ${ }^{16}$ The overall mortality for appendicitis is less than $1 \%{ }^{5}$

The overall frequency of surgical site infection (SSI) at Ward-26 of Jinnah Postgraduate Medical Centre, Karachi was found to be $21 \% .{ }^{17}$ The hypothesis that there was no correlation between surgical site infection after appendectomy with per-operative morphological appearance of appendix was supported by the data of the present study which revealed insignificant relationship between surgical site infection and per-operative morphological appearance of appendix ( $\mathrm{X} 2=$ 9.173, $P=0.164)$.

The overall SSI rate of $21 \%$ in our study is similar to the other reported findings by Adesunkanmi $\mathrm{AR}^{18}$, Wagner $\mathrm{JM}^{19}$ and Okobia $\mathrm{MN}^{20}$, who reported SSI rate $20.4 \%, 21.2 \%$, and $20.8 \%$ respectively.

Many international and few national studies evaluated the correlation of surgical site infection after appendicectomy with per-operative morphological appearance of appendix and reported variable results. One of these studies is by Gomes ${ }^{21}$ on 3,112 patients of acute appendicitis. He reported SSI rate of $1.1 \%$ in acutely inflamed, $17.1 \%$ in gangrenous and $36 \%$ in perforated appendicitis.

Another similar study by Kell MR et al. ${ }^{10}$ on 149 patients of acute appendicitis reported the overall SSI rate of $20 \%$ and SSI rate of $10 \%$ in acutely inflamed, $22.4 \%$ in gangrenous and $30.6 \%$ in perforated appendicitis.

In comparison to these two studies, SSI rate 
in our study group was higher in cases of gangrenous (35.5\%) and perforated (553.9\%) appendicitis. This is due to the fact that our study group included higher number of patients with complicated appendicitis as compared to abovementioned studies.

The highest incidence of SSI in our study group was among those who had complicated appendicitis, and it is similar to other studies which found SSI occurring in 5 to $10 \%$ of uncomplicated ${ }^{22}$ and 20 to $60 \%$ of complicated appendicitis. ${ }^{23,24}$

Intra-abdominal abscess (IAA) formation is the most common septical complication after perforated appendicitis. ${ }^{25}$ Studies by Aguilo $\mathrm{J}$ et $\mathrm{al}^{13}$ and Reid $\mathrm{RI}^{12}$ reported overall IAA formation rate of $2.1 \%$ and $1.4 \%$ respectively in their cases of acute appendicitis undergoing open appendicectomy. These results are almost similar to results of our study which showed overall IAA rate of $2 \%$. In cases of perforated appendicitis, IAA rate of as low as $2.6 \%{ }^{26}$ and as high as $38 \%$ has been reported in literature in different studies ${ }^{27}$ In our study $11.8 \%$ IAA occurred in cases of perforated appendicitis, which is consistent with the results reported by others.

Delay in diagnosis must be avoided in all patients. Preoperative delay period, which is divided into pre-admission delay (by patient) and post admission delay (by surgeon) effects on the course and outcome of acute appendicitis ${ }^{33}$, and can be disastrous for the patient ${ }^{28}$, as it is the main cause of gangrene and perforation, leading to increased frequency of postoperative wound infection. ${ }^{29}$ Cappendijk VC ${ }^{30}$ conducted a study and divided 130 patients of acute appendicitis into group A (diagnostic period within 48 hours) and group - B (diagnostic period 48 hours or more). Per operatively higher number of perforations (71\%) and post operatively higher number of SSI (78.9\%) was noted in group B. Carmen E et $\mathrm{al}^{31}$ and Ortega $\mathrm{LH}^{32}$ also found a close correlation with the development of SSI in appendicectomized patients and longer period of time for the disease. The results of our study are similar to results of these studies as higher number of post-operative complications $30(71.4 \%)$ occurred in patients having gangrenous or perforated appendicitis, who presented with duration of symptoms lasting for $>48$ to $>96$ hours.

Retrocaecal position of appendix is more prone to infection, perforation and gangrene. ${ }^{33}$ In our study $76 \%$ patients were having retrocaecal appendix and $12 \%$ were having pelvic appendix. These figures correlate with that reported by others ${ }^{34,35}$ and most of SSI in our study group developed in patients who were having retrocaecal appendix.

Surgical site infection rate increases with duration of operation. A study by Akhtar $S^{36}$ correlated the duration of surgery with postoperative wound infection and reported that in emergency operations with duration $>2$ hours to $<9$ hours, wound infection rate rose from $32.69 \%$ to 94.75 . In our study majority of appendicectomies were performed by junior residents and duration of operation as more (45 min to $>1$ hour) than usual ( 25 to $30 \mathrm{~min}$ ). This was also a contributory factor for development of SSI.

Simple ligation of appendix stump is better and safe procedure during appendicectomy ${ }^{37}$ as compared to invagination of stump because it shortens the operating time and there is less incidence of wound infection. This statement is supported by studies of Chaudhary $\mathrm{IA}^{37}$ and Gomes $\mathrm{AA}^{38}$ In our study SSI rate was high $(30 \%)$ in patients with invagination of appendiceal stump as compared to $20.5 \%$ SSI rate in patients with simple ligation of appendix stump.

Placement of transperitoneal drain in patients with perforated appendicitis is a controversial issue. Perovic $Z^{24}$ conducted a study on 56 patients of perforated appendicitis and compared the SSI rates I patients with an without transperitoneal drain and reported higher rate of SSI (65\%) in patients with drain as compared to $19 \%$ SSI in patients without drain placement. Our study shows SSI rate of $55.8 \%$ in cases of perforated appendicitis, where silicon drain was placed in all cases of perforated appendicitis.

Primary closure of skin and subcutaneous tissue after appendicectomy for perforated 
or gangrenous appendicitis is not associated with increased risk of incision infection when compared with delayed closure. ${ }^{39}$ Studies by Chatwiriyacharoen $\mathrm{W}^{40}$ and Burnweit $\mathrm{C}^{41}$ and Rucinski $\mathrm{J}^{42}$ all concluded that lower rates of infection fully justifies the policy of primary wound closure in cases of perforated appendicitis. Results of primary wound closure in all cases of complicated appendicitis in our study group were significantly better.

The success of antibiotic prophylaxis is assured only when the chosen drug with a targeted spectrum is available at the critical moment at the correct site and in sufficiently high concentration to prevent bacterial contamination of surgical field. ${ }^{43}$ In our study group all patients received triple therapy as prophylaxis but study by Malik $\mathrm{SN}^{44}$ reported that monotherapy with metronidazole is as effective as triple therapy in cases of nonperforated acute appendicitis. ${ }^{45}$

\section{CONCLUSION}

It was not possible to establish a relationship between SSI and per-operative morphological appearance of appendix. Frequency of SSI reported here $(21 \%)$ is comparable with literature. We recommended that avoiding delay in diagnosis, use of peri-operative antibiotics, sound surgical technique to avoid wound contamination and continuing surveillance is necessary to further reduce $S S I$ rates after open appendicectomy.

\section{Copyright@ 25 May, 2019.}

\section{REFERENCES}

1. Saeed Z. Acute appendicitis; Clinical correlation of with histopathological diagnosis: A retrospective study. Professional Med J 2014; 21(6):1139-1143.

2. ALI, N., SADIQ, M., BACHA, J., HADI, G. Correlation of clinical and histological diagnosis of acute appendicitis. Journal of Postgraduate Medical Institute (Peshawar - Pakistan), North America, 17, sep. 2011. Available at: <http://www.jpmi.org.pk/index.php/jpmi/ article/view/835> . Date accessed: 27 Jul. 2017.

3. Roche-Nagle G1, Gallagher C, Kilgallen C, Caldwell M. Stump appendicitis: A rare but important entity. Surgeon. 2005 Feb; 3(1):53-4.
4. Cho, J., Lee, D., Sung, K., Baek, J., \& Lee, J. (2017). Clinical implication of discrepancies between surgical and pathologic diagnoses of acute appendicitis. Annals of Surgical Treatment and Research, 93(1), 43-49. http://doi.org/10.4174/ astr.2017.93.1.43.

5. Omari AH, Khammash MR, Qasaimeh GR, Shammari AK, Yaseen MKB, Hammori SK. Acute appendicitis in the elderly: Risk factors for perforation. World Journal of Emergency Surgery: WJES. 2014; 9:6. doi:10.1186/1749-7922-9-6.

6. Inceso L. Diagnosis of appendicitis. Can R Rural Med 2002; 7:26-9.

7. Ruffolo C, Fiorot A, Pagura G, et al. Acute appendicitis: What is the gold standard of treatment? World Journal of Gastroenterology : WJG. 2013; 19(47):8799-8807. doi:10.3748/wjg.v19.i47.8799.

8. Margenthaler JA1, Longo WE, Virgo KS, Johnson FE, Oprian CA, Henderson WG et al. Risk factors for adverse outcomes after the surgical treatment of appendicitis in adults. Ann Surg. 2003 Jul; 238(1):5966.

9. Nichols RL. Preventing surgical site infections. Clinical Medicine and Research. 2004; 2(2):115-118.

10. Kell MR1, Power K, Winter DC, Power C, Shields C, Kirwan WO et al. Predicting outcome after appendicectomy. Ir J Med Sci. 2003 Apr-Jun; 172(2):63-5.

11. Nshuti, R., Kruger, D., \& Luvhengo, T. E. (2014). Clinical presentation of acute appendicitis in adults at the Chris Hani Baragwanath academic hospital. International Journal of Emergency Medicine, 7, 12. http://doi.org/10.1186/1865-1380-7-12.

12. Reid RI, Dobbs BR, Frizelle FA. Risk factors for postappendicectomy intra-abdominal abscess. Aust N Z J Surg. 1999; 69:373-4.

13. Aguiló J, Peiró S, Muñoz C, García del Caño J, Garay $\mathrm{M}$, Viciano $\mathrm{V}$ et al. Adverse outcomes in the surgical treatment of acute appendicitis. Cir Esp. 2005 Nov; 78(5):312-7.

14. Harahsheh B, Hiyasat B, Abulail A, Al-Basheer M. Management of wound infection after appendectomy: Are parenteral antibiotics useful? East Mediterr Health J. 2002 Jul-Sep; 8(4-5):638-44.

15. Nasir Ali, Asghar Javaid. Role of tube Cecostomy in preventing post appendectomy abscess and fistula formation. Pak J Med Sci Jul - Sep 2005; 21 (3):285-8.

16. Bhopal FG, Khan JS, Iqbal M. Surgical audit of acute appendicitis. J Coll Physicians Surg Pak 1999; 9:223-6. 
17. Perović Z. Drainage of the abdominal cavity and complications in perforating appendicitis in children. Med Pregl. 2000 Mar-Apr; 53(3-4):193-6.

18. Akinkunmi EO, Adesunkanmi AR, Lamikanra A. Pattern of pathogens from surgical wound infections in a Nigeria hospital and their antimicrobial susceptibility profiles. Afr Health Sci. 2014; 14(4):802-9.

19. Wagner JM, McKinney WP, Carpenter JL. Does this patient have appendicitis? JAMA. 1996 Nov 20; 276(19):1589-94.

20. Masood Jawaid, Zubia Masood, Syed Abdullah Iqbal. Post-operative complications in a general surgical ward of a teaching hospital. Pak J Med Sci April - June 2006 Vol. 22 No. $2171-175$.

21. Guzmán-Valdivia Gómez G. An useful classification for acute appendicitis. Rev Gastroenterol Mex. 2003 Oct-Dec; 68(4):261-5.

22. Tönz M, Schmid P, Kaiser G. Antibiotic prophylaxis for appendectomy in children: Critical appraisal. World J Surg. 2000 Aug; 24(8):995-8.

23. Hell K. Antibiotic prophylaxis in appendectomy. Often neglected--but necessary. Zentralbl Chir. 1998; 123 Suppl 4:82-4.

24. Salam IM, Abu Galala KH, el Ashaal YI, Chandran VP, Asham NN, Sim AJ. A randomized prospective study of cefoxitin versus piperacillin in appendicectomy. $J$ Hosp Infect. 1994 Feb; 26(2):133-6.

25. Horst M, Eich G, Sacher P. Postappendectomy abscess--the role of fecoliths. Swiss Surg 2001; $7(5): 205-8$.

26. I.A. Chaudhary, I.A. Chaudhary, A.A. Mallhi, A. Banols it necessary to invaginate the stump after appendicectomy? Pak J Med Sci 2005; 1; 35-38.

27. Piskun G, Kozik D, Rajpal S, Shaftan G, Fogler $R$ Comparison of laparoscopic, open, and converted appendectomy for perforated appendicitis. Surg Endosc. 2001 Jul; 15(7):660-2.

28. Saeed Amer. Protocol based diagnosis of Appendicitis. J Postgrad Med Inst Apr - Jun 2004; 18(2):280-3.

29. Gottrup F, Melling A, Hollander DA. An overview of surgical site infection: Aetiology, incidence and risk factors. EWMA J 2005; 5:11-15.
30. V Cappendijk and F Hazebroek. The impact of diagnostic delay on the course of acute appendicitis. Arch Dis Child. 2000 Jul; 83(1): 64-66.

31. Vergas CEP, Lopes A, Gil JRD, Montoya RMR, Guzman WRA. Surgical wound infection in appendicectomized patients in the surgical service of hospital III Essalud - chimbote. Rev Gastroenterol Peru 2004; 24:43-9

32. Ortega León LH1, Vargas Domínguez A, Miranda Fraga P. The local complications of appendicitis Rev Gastroenterol Mex. 1994 Jul-Sep; 59(3):223-6.

33. Muhammad Ahmad, Imtiaz Ahmad, Khalid Mahmood Gill. Retrocecal Appendix Profess Med J Apr - Jun 2002;9(2):135-8.

34. Gulzar S, Umar S, Dar GM, Rashed R. Acute appendicitis-importance of clinical examination in making a confident diagnosis. Pak J Med Sci 2005; 21: 125-32.

35. Nazir Ahmad, Khalid Javed Abid, Aamer Zaman Khan, Syed Tahir Ahmad Shah.Acute appendicitis - incidence of perforated appendicitis. Ann King Edward Med Uni Oct - Dec 2004; 10(4):356-8.

36. Salman Akhtar, Khalid Masood Gond, Mohammed Ahmed, Yar Mohammad, Abdul Rouf Goraya, Fowad Karim et al. Surgical wound site infection - Our experience. Ann King Edward Med Uni Jul - Sep 2001; $7(3): 211-2$.

37. Page CP, Bohnen JM, Fletcher JR, McManus AT, Solomkin JS, Wittmann DH Antimicrobial prophylaxis for surgical wounds. Guidelines for clinical care. Arch Surg. 1993 Jan; 128(1):79-88.

38. Gomes AAV, Garibay LJL. Effect of the method of treatment of appendicular stump on the frequency of post appendectomy wound infection. Cir ciruj 1998; $66 ; 66-9$

39. Taylor E1, Berjis A, Bosch T, Hoehne F, Ozaeta M. The efficacy of postoperative oral antibiotics in appendicitis: A randomized prospective doubleblinded study. Am Surg. 2004 Oct; 70(10):858-62.

40. Chatwiriyacharoen W. Surgical wound infection postsurgery in perforated appendicitis in children. $\mathrm{J}$ Med Assoc Thai. 2002 May; 85(5):572-6.

41. Burnweit C1, Bilik R, Shandling B. Primary closure of contaminated wounds in perforated appendicitis. $J$ Pediatr Surg. 1991 Dec; 26(12):1362-5. 
42. Rucinski J1, Fabian T, Panagopoulos G, Schein M, Wise L. Gangrenous and perforated appendicitis: A metaanalytic study of $\mathbf{2 5 3 2}$ patients indicates that the incision should be closed primarily. Surgery. 2000 Feb; 127(2):136-41.

43. Anwer M, Manzoor S, Muneer N, Qureshi S. Compliance and effectiveness of WHO surgical safety check list: A JPMC Audit. Pak J Med Sci. 2016 Jul-Aug; 32(4):8315.
44. Sohail Noor Malik, Muhammad Afzal Sheikh. Acute appendicitis: Metronidazole as monotherapy and early intake of oral fluids. Ann King Edward Med Uni Apr - Jun 2000; 2(6):163-4

45. Kasatpibal N, Jamulitrat S, Chongsuvivatwong V. Standardized incidence rates of surgical site infection: A multicenter study in Thailand. Am J Infect Control. 2005 Dec; 33(10):587-94.

\begin{tabular}{|c|c|c|c|}
\hline \multicolumn{4}{|c|}{ AUTHORSHIP AND CONTRIBUTION DECLARATION } \\
\hline Sr. \# & Author(s) Full Name & Contribution to the paper & Author(s) Signature \\
\hline 1 & $\begin{array}{l}\text { Rehana Firdos } \\
\text { Irfan Haider Abdi }\end{array}$ & $\begin{array}{l}\text { Interpretation and writing } \\
\text { manuscript. } \\
\text { Designing of methodology. }\end{array}$ & \\
\hline 3 & Qambar Ali Laghari & Data collection procedure. & \\
\hline 4 & Mujeeb ur Rahman Sahito & $\begin{array}{l}\text { Data analysis and statistical } \\
\text { help. }\end{array}$ & \\
\hline 5 & Naimatullah Kalhoro & $\begin{array}{l}\text { Data Entry SPSS and other } \\
\text { technical help. }\end{array}$ & - \\
\hline 6 & Sikandar Munir Memon & $\begin{array}{l}\text { References, citation } \\
\text { manager \& designing of } \\
\text { results and charts and } \\
\text { Graphs in manuscript. }\end{array}$ & \\
\hline
\end{tabular}

